\title{
Lipaemia retinalis in a 29-day-old infant with type 1 hyperlipoproteinaemia
}

\author{
S HAYASAKA, ' T FUKUYO,' M KITAOKA, ${ }^{1} \mathrm{H}$ SUZUKI, ${ }^{2} \mathrm{~K}$ OMURA, ${ }^{2} \mathrm{Y}$ KONDO, ${ }^{2}$ \\ AND M NAKAGAWA ${ }^{2}$
}

From the Departments of 'Ophthalmology and ${ }^{2}$ Paediatrics, Tohoku University School of Medicine, Sendai, Japan

SUMMARY A 29-day-old infant born of consanguineous parents had type 1 hyperlipoproteinaemia associated with lipaemia retinalis. Biochemical analyses disclosed hypertriglyceridaemia, hyperchylomicronaemia, and lipoprotein lipase deficiency. Ophthalmoscopically all retinal vessels had the creamy appearance of lipaemia retinalis. The plasma lipoprotein levels and fundus condition became normal after her ingestion of fat was limited. To our knowledge this is the youngest patient reported with type 1 hyperlipoproteinaemia associated with lipaemia retinalis.

Type 1 hyperlipoproteinaemia is an autosomal recessively inherited disorder characterised by hyperchylomicronaemia and hypertriglyceridaemia. ${ }^{1}$ To date fewer than 100 cases of the disorder have been reported. ${ }^{2}$ Lipaemia retinalis is peculiar in this disorder. ' 2 However, the fundus picture has been rarely shown. ${ }^{3}$ We describe lipaemia retinalis in a 29-day-old infant with type 1 hyperlipoproteinaemia.

\section{Case report}

An apparently normal baby was delivered on 12 July 1983 after a full-term uneventful pregnancy. Her birth weight was $3280 \mathrm{~g}$. The parents, who were first cousins, and a 2-year-old brother were in good health (Fig. 1). The infant was breast-fed. When a blood sample was obtained from the cubital vein for newborn screening at 5 days of age, the patient's serum was observed to be milky. On 4 August she was referred to the Tohoku University Hospital for further examination.

Biochemical analyses disclosed a slightly elevated serum cholesterol level $(400 \mathrm{mg} / \mathrm{dl}(10.4 \mathrm{mmol} / \mathrm{l})$; normal, $1.30-250 \mathrm{mg} / \mathrm{dl}(3.4-6.5 \mathrm{mmol} / \mathrm{l}))$ and a markedly increased serum triglyceride concentration $(3000 \mathrm{mg} / \mathrm{dl}(33.9 \mathrm{mmol} / \mathrm{l})$; normal, $35-130 \mathrm{mg} / \mathrm{dl}$ $(0.4-1.5 \mathrm{mmol}))$. During the examination serum triglyceride level sometimes increased to 15000

Correspondence to S Hayasaka, MD, Department of Ophthalmology, Tohoku University School of Medicinc, Sendai, Miyagi 980, Japan. $\mathrm{mg} / \mathrm{dl}(169 \cdot 5 \mathrm{mmol} / \mathrm{l})$. The serum phospholipid level was within normal range. The presence of hyperchylomicronaemia was demonstrated by agar-gel electrophoresis. Apolipoprotein CII assayed by immunodiffusion was normal. Lipoprotein lipase activity in postheparin plasma examined by the method of Murase and associates, ${ }^{4}$ based on immunoprecipitation of hepatic triglyceride lipase, was negligible. The deficiency of lipoprotein lipase was thus confirmed in this case. Other laboratory data, including blood cell counts, electrolytes, liver function tests, estimations of glucose, ammonia, and amylase, and immunoelectrophoresis, were normal. The liver and spleen were not enlarged.

At 29 days of age an ophthalmic examination was performed. A few lipid depositions, or eruptive xanthoma, were noted in the upper eye lids. Ocular tension was normal to palpation. Pupils were isocoric

\section{Pedigree}

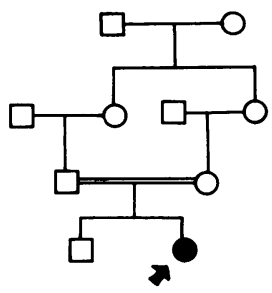

= consanguineous marriage

affected female

7 proband

Fig. 1 Pedigree. 


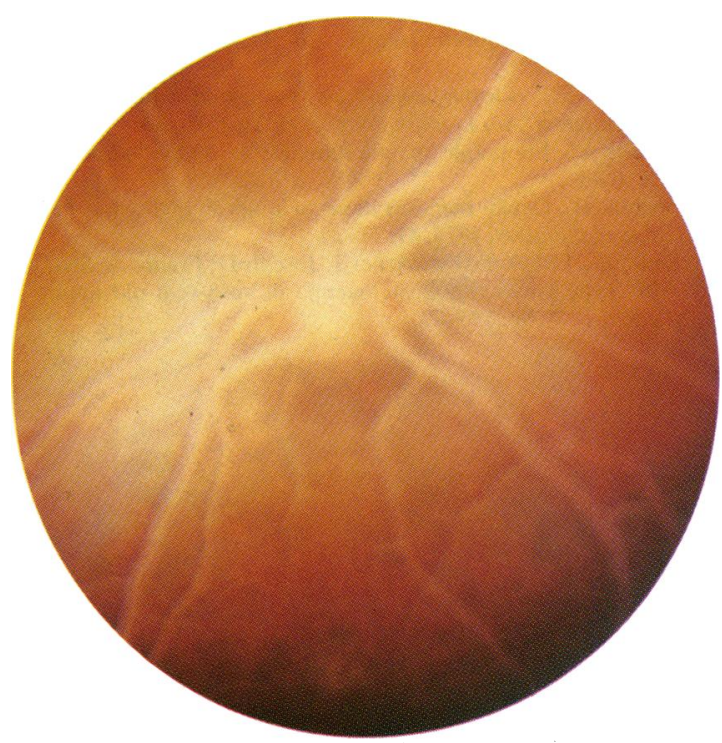

Fig. 2 Fundus photograph of left eye of proband shows the whitish optic disc and creamy retinal vessels, i.e. lipaemia retinalis.

and reactive. The corneas were transparent, and corneal arcus or crystalline was absent. Xanthoma was not seen in the iris. The optical media was clear.

Ophthalmoscopically the optic discs were whitish but not swollen. All vessels had a creamy appearance, and it was difficult to differentiate retinal arterioles from veins (Fig. 2). The extravasation of lipid material from the vessels was not prominent. The retina seemed normal, and no retinal haemorrhage was noted. The scotopic electroretinogram response was normal.

After the patient's ingestion of fat was stringently limited, serum cholesterol, triglyceride, and chylomicron levels were reduced: serum cholesterol, 200 $\mathrm{mg} / \mathrm{dl}(5.2 \mathrm{mmol} / \mathrm{l})$; triglyceride, $300 \mathrm{mg} / \mathrm{dl}(3.4$ $\mathrm{mmol} / \mathrm{l}$ ); and chylomicron, normal levels within several days. When the triglyceride concentration dropped below about $2500 \mathrm{mg} / \mathrm{dl}(28.2 \mathrm{mmol} / \mathrm{l})$, the fundus changes cleared (Fig. 3). The eruptive xanthoma disappeared thereafter.

\section{Discussion}

Lipaemia retinalis is a manifestation of excess triglyceride in the bloodstream: the retinal vessels are found to be milky or creamy when triglyceride levels rise to 2000 to $2500 \mathrm{mg} / \mathrm{dl}(22.6$ to $28.2 \mathrm{mmol} / \mathrm{l})$ or greater. ${ }^{2}$ Lipaemia is seen not only in retinal vessels but also in limbal vessels. ${ }^{5}$ Lipaemia retinalis has been graded 0 to III by Vinger and Sachs. ${ }^{6}$ Fundus changes in our case were grade III according to this

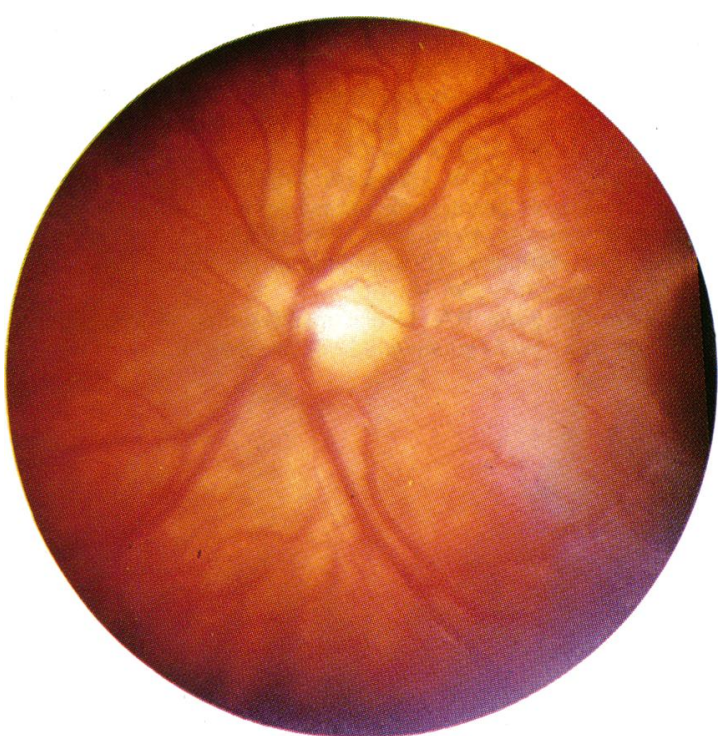

Fig. 3 After the patient's ingestion of fat was stringently limited, the fundus changes cleared.

classification. Increased cholesterol levels alone do not cause the milky plasma. ${ }^{2}$

Lipaemia retinalis is reported in cases of types I, II, IV, and V hyperlipoproteinaemia. ${ }^{3}$ Type I hyperlipoproteinaemia is characterised by hyperchylomicronaemia and hypertriglyceridaemia and confirmed by lipoprotein lipase deficiency. ${ }^{2}$ The plasma lipoprotein levels and fundus condition usually respond to treatment with a low-fat diet, as in our case.

Fundus photographs of lipaemia retinalis have been shown mostly for type $\mathrm{V}$ hyperlipoproteinaemia secondary to diabetes. ${ }^{67}$ The fundus picture is not found in cases of idiopathic or retention (former name of type I) hyperlipaemia,${ }^{x y}$ and has been found only in 18- and 28-year-old men with type I hyperlipoproteinaemia. ${ }^{311}$ Type I hyperlipoproteinaemia in an 8-day-old infant has been reported, but she lacked eruptive xanthoma and lipaemia retinalis." To our knowledge our present case is the youngest patient with type 1 hyperlipoproteinaemia associated with lipaemia retinalis.

The authors thank Professor K Mizuno for his advice and Ms M Gere for her editing. This study was supported in part by the grants from the Ministrics of Education and Welfare of Japan.

\section{References}

1 Nikkilä EA. Familial lipoprotcin lipase deficiency and related disorders of chylomicron metabolism. In: Stanbury JB. Wyngaarden JB, Fredrickson DS, Goldstein JL, Brown MS, cds. Metabolic basis of inherited diseases. 5th cd. New York: McGraw-Hill, 1983: 622-42. 
2 Winder AF. Disorders of lipid and lipoprotein metabolism. In Garner A, Klintworth GK, eds. Pathobiology of ocular disease. New York: Dekker, 1982: 1047-75.

3 Spacth GL. Inborn errors of metabolism affecting the eye. In: Harley R, ed. Pediatric ophthalmology. 2nd ed. Philadelphia: Sanders, 1983; 2: 1070-143.

4 Murasc T, Yamada N, Ohsawa N, Kosaka K, Morita S, Yoshida $\mathrm{S}$. Decline of postheparin plasma lipoprotein lipase in acromegalic patients. Metabolism 1980; 29: 666-72.

5 Bron AJ, Williams HP. Lipaemia of the limbal vessels. Br J Ophthalmol 1972; 56: 343-6.

6 Vinger PF, Sachs BA. Ocular manifestation of hyperlipoprotcinacmia. Am J Ophthalmol 1970; 70: 563-73.
7 Kurz GH, Shakib M. Sohmer KK, Friedman AH. The retina in type 5 hyperlipoproteinaemia. Am J Ophthalmol 1976; 82: $32-43$.

8 Dunphy EB. Ocular conditions associated with idiopathic hyperlipemia. Am J Ophthalmol 1950; 33: 1579-86.

9 Davies WS. Idiopathic lipemia retinalis. Arch Ophthalmol 1955: 53: $105-8$.

10 Spacth GL. Ocular manifestations of lipoprotein disease. J Cont Educ Ophthalmol 1979; 41: 11-24.

11 Sadon N, Drucker MM, Arber I, Joseph D, Franco S, Shapiro MS. Type I hyperlipoprotcinacmia in an 8-ycar-old infant. $J$ Pediatr 1977; 90: 775-77. 